\title{
MAXIMIZATION OF ENERGY IN THE OUTPUT OF A LINEAR SYSTEM
}

D. G. Dudley

Apr11 1.5, 1976

Prepared for U.S. Energy Research \& Development

Administration under contract No. W-7405-Eng-48
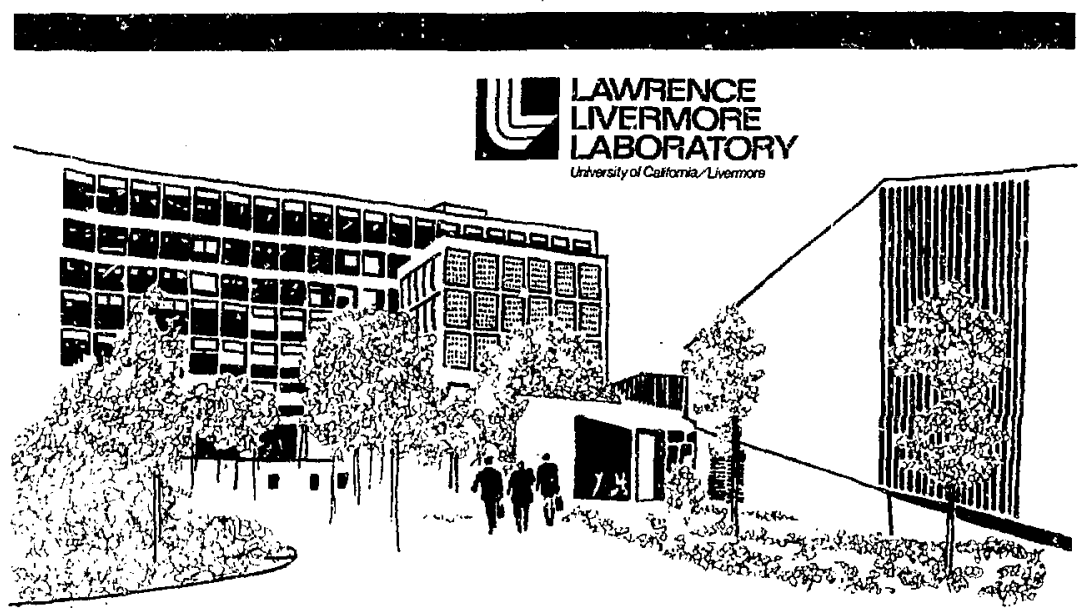


\section{NOTICE}

"This report was prepared as in eccount of work sponsored by the United Sintes Government. Nelthet the United States nos the Vinited States Energy Research \& Development Adminiatrotlon, nor any of thele employecs, nor any of theit contractors, subcontractors, of their employees, makes any warranty, express or implied, or assumes any tesal linbulty or responniblitity for the accuracy, completeness or usofulness of eny information, apperatiss, product or process disclosed, of represents that its use would not infringe privately-owned righis."

Printed in the United States of America

$$
\text { Available from }
$$

National Technical Information Service

U.S. Department of Commerce

5285 Port Royal Road

Springfield, VA 22161

Price: Printed Copy \$ ; Microfiche \$2.25

\begin{tabular}{|c|c|c|}
\hline $\begin{array}{c}\text { Domentic } \\
\text { Price }\end{array}$ & Page Aange & $\begin{array}{l}\text { Domestlo } \\
\text { Price }\end{array}$ \\
\hline$\$ 3.50$ & $326-350$ & 10.00 \\
\hline 4.00 & $351-375$ & 10.50 \\
\hline 4.50 & $376-400$ & 10.75 \\
\hline 5.00 & $401-425$ & 11.00 \\
\hline 5.25 & $426-450$ & 11.75 \\
\hline 5.50 & $451-475$ & 12.00 \\
\hline 6.00 & $476-500$ & 12.50 \\
\hline 7.50 & $501-525$ & 12.75 \\
\hline 7.75 & $526-550$ & 13.00 \\
\hline 8.00 & $551-575$ & 13.50 \\
\hline 9.00 & $576-600$ & 13.75 \\
\hline 9.25 & 601-up & $\bullet$ \\
\hline 9.75 & & \\
\hline
\end{tabular}

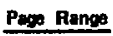

001-025

026-050

$051-075$

$076-100$

$101-125$

$126-150$

$151-175$

$176-200$

201-225

226-250

$25 \mathrm{t}-275$

$276-300$

$301-325$
9.75
Domestic

10.00

10.50

10.75

11.00

12.50

3.00

13.75

Add $\$ 2.50$ for each additionel 100 page increment from 601 to 1,000 pages: sdd $\$ 4.50$ for each \&dditional 100 page increment over 1,000 pages. 


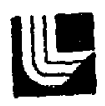

LAWRENCE LIVEFMOAE LABK HATTOFY

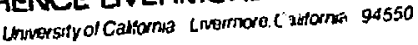

\section{UCKL-51887 \\ MAXIMIZATION OF ENERGY IN THE OUTPUT OF A LINEAR SYSTEM}

D. C. Dudley

MS. date: Antil 15, 1976

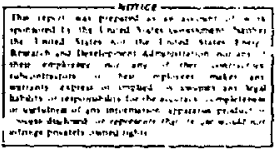




\section{Foreword}

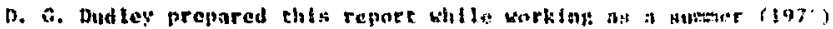

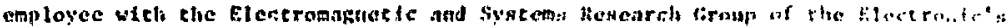

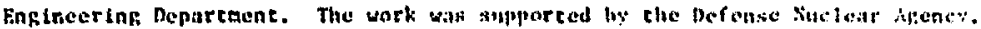

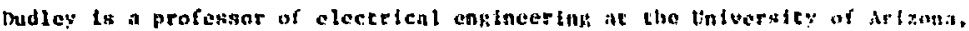
Tucson. 


\section{MAXIMIZATION OF ENERGY IN THE OUTPUT \\ OF A LINEAR SYSTEM}

\section{Abstract}

In this report, we conslder a time-lifited signal which, witen passed chroukl a linear system. maximfzes the cotal autput energy. Previous work has shown that the solution is given by the elgenfunction associated with the maximum cipenvalue in a Hibert-Suhteld incegral equacion. Nalytical res. its are ivaliable for the case where che transfer function is a low pitss rilter. This work is extended by obtaining a numerical solution to th:- intogral cquation which al lows results for reasonably general cransfer runcelons.

\section{Introduction}

Conslder a Iinear system with input $f(t)$ and output $g(t)$. For $f(t)$ time-limlted [-T,T] and of spectfied energy, Chalk has shown that the total energy in the output is maximized through a consideration of the linciar integral equation

$$
\lambda f(\tau)=\int_{-T}^{T} f(\tau) K(c-\tau) d \tau .
$$

The "optinal" $f(t)$ is that particular eigenfunction $f(t)$ associated wa. the thaximum eigenvalue $\lambda_{1}$ obcained in the solucion to Eq. (1). Chalk ias obcalred an analytical solution to Eq. (b) for the case where the trat.sfer function $1(w)$ is the first-order Butterworth low-pass filter

$$
H(w)=\frac{\alpha}{\alpha+1 \omega}
$$

Chalk also gives approxituate solutions for the case where the transfer function 18 an ideal lowmpass filter 


$$
H(\omega)=\left\{\begin{array}{lll}
1 & |\omega|<\omega_{0} \\
0 & |\omega|>\omega_{0}
\end{array}\right\} .
$$

Slepian and Pollak ${ }^{2}$ have extended the results by noting that for the case of the ideal low-pass filter, Eq. (1) defines cercain of the angular prolate spheroidal functions, ${ }^{3}$ a Eact which allows for expression of the ideal low'pass filter reaults in terms of known functions.

In this report, we take a different point of view, abandoning the search for further analytical solutions in favor of obtaining an efflclent numerical solution to $\mathrm{Eq}$. (1). Our reason is that our application is in electromagnetics witers the transfer function is often known only in cerms of discrete experimental data or discrete data from numerical solutions to the electromagnetic boundary value problem. The results hereln are reasonably complete in one sense and only preliminary in another. We have produced an efficient numerical technique for the reduction of Eq. (1) and have compared the results favorably both with Chalk and with Slepian and Pollak. In addition we have produced optimum pulses for the fmportant case of a single-resonance transfer function. On the other hand, the numerical technique affords access to a large range of transfer functions which we have not begun to consider and In this sense the results are only preliminary. We make some spectfic comments concerning this later in the report.

\section{Background}

Let the energy in the Input $f(t)$ to a Inear system be given by

$$
E_{I}=\int_{-T}^{T} t^{2}(t) d t
$$

Let the energy in the output $g(t)$ be given by

$$
E_{0}=\int_{-\infty}^{\infty} g^{2}(t) d t
$$


Hy Parseval's theorem, 4 this result may be given in terms of the frequency spectrum of the output $G(\omega), v i z$ :

$$
F_{0}=\frac{1}{2 \pi} \int_{-\infty}^{\infty}|G(\omega)|^{2} d \omega
$$

If $F(\omega)$ Is the frequency spectrum of the Input and $H(\omega)$ the sysiem transter function,

$$
E_{0}=\frac{1}{2 \pi} \int_{-\infty}^{\infty}|E(\omega) H(w)|^{2} d \omega,
$$

or, In terms of the Fourier transforms of $F$ and $F^{*}$,

$E_{0}=\frac{1}{2 \pi} \int_{-\infty}^{\infty}|H(\omega)|^{2} \int_{-T}^{T} f(\tau) e^{-1 \omega \tau} d \tau \int_{-T}^{T} f(s) e^{I \omega x} d x d \omega$.

An interchange of integration produces the result

$$
E_{0}=\int_{-T}^{T} \int_{-T}^{T} f(\tau) f(x) K(x-T) d x d T,
$$

where

$$
K(t)=\frac{1}{2 \pi} \int_{-\infty}^{\infty}|H(\omega)|^{2} e^{1 \omega t} d \omega .
$$

We wish to find an $f_{1}(t)$, optimum in the sense that it maximizes the double integral in Eq. (9), subject to the constraint in Eq. (4). Thic: problem is classic in the calculus of variations (see Appendix $A$ ) and his the following solution. The function $f_{1}(t)$ must satisfy the integral equation given by Eq. (1), Specifically,

$$
\lambda_{1} f_{1}(t)=\int_{-T}^{T} f_{1}(\tau) K(t-\tau) d \tau,
$$


where $f_{1}$ is the eigenfunction corresponding to the maximum eigenvalue $x_{1}$. Substitution of Eq. (11) Into Eq. (9) yields

$$
E_{0}=\lambda_{1} E_{I}
$$

A final comment is in order concerning the properties of the solutions to Eq. (1). We note that the expression for the kernal function in Eq. (10) may be writien

$$
K(t)=\frac{1}{\pi} \int_{0}^{\infty}|H(\omega)|^{2} \cos \omega t d \omega .
$$

where we have used the even property of $|\mathrm{H}(\omega)|^{2}$. We therefore conclude that the kernal is symmetric, viz:

$$
K(t)=K(-t)
$$

The result is that the eigenfunctions obcained in the solution to f.q. (1) are orthogonal and corresponding eigenvalues are real. 5 In addition,

$$
\lambda_{1}>\lambda_{2}>\lambda_{3}>\ldots
$$

so that we may legitimately seek the maximum eigenvalue.

\section{Normalization of Results}

In order to produce a convenient normalization of the results to follow, we consider the all-pass transfer function

$$
|H(\omega)|=1
$$

From the Eourtar transform palr

$$
\delta(t) \longrightarrow 1
$$

we ootain in Eq. (I)

$$
\lambda f(t)=\int_{-T}^{T} f(\tau) \delta(t-T) d \tau
$$


whth the sulut lon

$$
\lambda=i \text {. }
$$

We shill therefore adopt the norinalization in general that

$$
\operatorname{mix}|1+(w)|=1
$$

This means that

$v_{0}=\frac{1}{2 \pi} \int_{-\infty}^{\infty}|F(\omega) H(\omega)|^{2} d \omega \leq \frac{1}{2 \pi} \int_{-\infty}^{\infty}|F(\omega)|^{2} d \omega=E_{I}$

so that, whth our normalization,

$$
1 \leq 1
$$

\section{Numerical Reduction of Integra! Equation}

To obtain a numerical solution to the integral equation In Eq. (1), we ul111ze the method of morents. ${ }^{6}$ We expand $f(t)$ in a sequence of pulse functlons

$$
f(t)=\sum_{n=-N}^{N} a_{n} p_{n}(t)
$$

where

$$
P_{n}(t)=\left\{\begin{array}{ll}
1 & n \Delta-\frac{1}{2}<t<n \Delta+\frac{1}{2} \\
0 & \text { otherwise }
\end{array}\right\}
$$

and

$$
\Delta=\frac{T}{N+\frac{2}{2}}
$$

Substitution Into Eq. (1) ytelds

$$
\lambda \sum a_{n} p_{n}(t)=\sum a_{n} q_{n}(t)
$$


where

$$
q_{n}(t)=\int_{n_{L}-\frac{d}{2}}^{n \therefore+\frac{\hat{H}}{2}} k(t-\tau) d \tau .
$$

We next multifly both sides by $\xi(t-m i)$ and integrate $(-t, t)$ lo lat

$$
\sum a_{n} s_{m n}=\sum a_{n} q_{n}(m \Delta) .
$$

We recognize Eq. (28) as a matrix equation

$$
\left[a_{m n}\right]\left[a_{n 1}\right]=x\left[a_{n}\right] \text {, }
$$

where $\left[\ell_{m \pi}\right]$ is a square symetric matrix with elements given by

$$
l_{m n}=\int_{\left(|n-m|-\frac{1}{2}\right) \Delta}^{\left(|n-m|+\frac{1}{2}\right) \Delta} k(x) d x
$$

The mat:ix given by Eq. (29) can be solved for its eigenvalues and astiociated eigenfunctions by utilizing a series of subroutines contained in a package called Eispack. ${ }^{7}$ The appropriate subroutinis and their function for this problem are as follows:

- TRED1 - transforms the real symmetric matrix in Fq. (30) to tridiagonal symmetric.

- BSTURM - calculates an interval containtrg a specified number of largest efgenvalues.

- TSTURM - finds the eigenvalues in the interval caiculated by BSTLRI and the associated eigenfun-tions of the tridiagonal matrix.

- TRBAKl - back transforms the eigenfunctions of the tridiagonal matrix to find the eigenfunctions of the real symmetric matrix. 
A computer program has becon wriceen to perform the numerica! reduction of the :ategral cequation in fiq. ( $)$. The pregram can operate in one of tho modes. In the first mode, the program accepts numerical data representin a transier function $\|(\omega)$ and parforms the inverse fourier transfora indicated in $\mathrm{kg}$. (13) to produce the kernal function $\mathrm{k}(\mathrm{t})$. The cosine form of che rrinsform in Eq. (13) djffers only by a multiplicative factor of two from the inverse transform applicable to a causal real function, We therefore use subroutine $L F T L O N^{8}$ co obtain this result. Once $K$ fit $^{\circ}$ has been calculaced, the square matrix [ ${ }_{\text {mn }}$ ] is obtained by numeriral quadrature. The abrve subroutines irom EISPACK are then employed to give the required maximum tigenvalue and associated eigesfunction. In the second mode, the prouram depends on the user supplying analytical expresstons for $H(4)$ and for $K(t)$ in two function subprograms. In this case the necessity of performing a numerical itiverse transform is eliminated. Beyoud this difference, the reminder of the program functions as in the tirst mode. A listing of the proptram is included in Appendix $B$.

\section{Numerical Results}

The program described above was first used to perform checks agaiast the resultis of Chalk (Ref. 1, p, 89) and Slepian and Poliak (Ref. 2, pp. 47-51). In al1 cases, the results duplicated theirs and w111 not be repeaced here. Slepian's and Pollak's zesults are reprozuced in a well-known textbook by Papoulis (Ref. 4, p. 69)]. After these checks were performed, we considered the case of a single resonance transfer function, given by

$$
H(\omega)=\frac{2 \alpha i \omega}{(\alpha+i \omega)^{2}+z^{2}} \text {. }
$$

From Eq. (31), the kernal function $K(t)$ may be found analytically by closing the integral given in Eq. (10) along a sciniclecle through tive top nalf of the complex w-plane and using the ca..culus of residues. This procedure gives the result for $t>0$ only; since $K(t)$ has been shown to be symmetric, however, this is sufficient. The result is

$$
K(t)=\alpha e^{-\alpha|t|}\left(\cos \beta|t|-\frac{\alpha}{\beta} \sin \beta|t|\right),
$$


where

$$
\beta=\left(\omega_{0}^{2}-\alpha^{2}\right)^{\frac{1}{2}}, \omega_{0}>\alpha \quad
$$

Since the analytical expressions are avallable in this case, the program operates in the second mode.

In Fig. 1, we show the magnitude of the transfer function in desibels for the single resonant case. We selected parameter values of $\alpha=9.16 \times 10^{6}$ and $f_{0}=48.6 \mathrm{MHz}$.

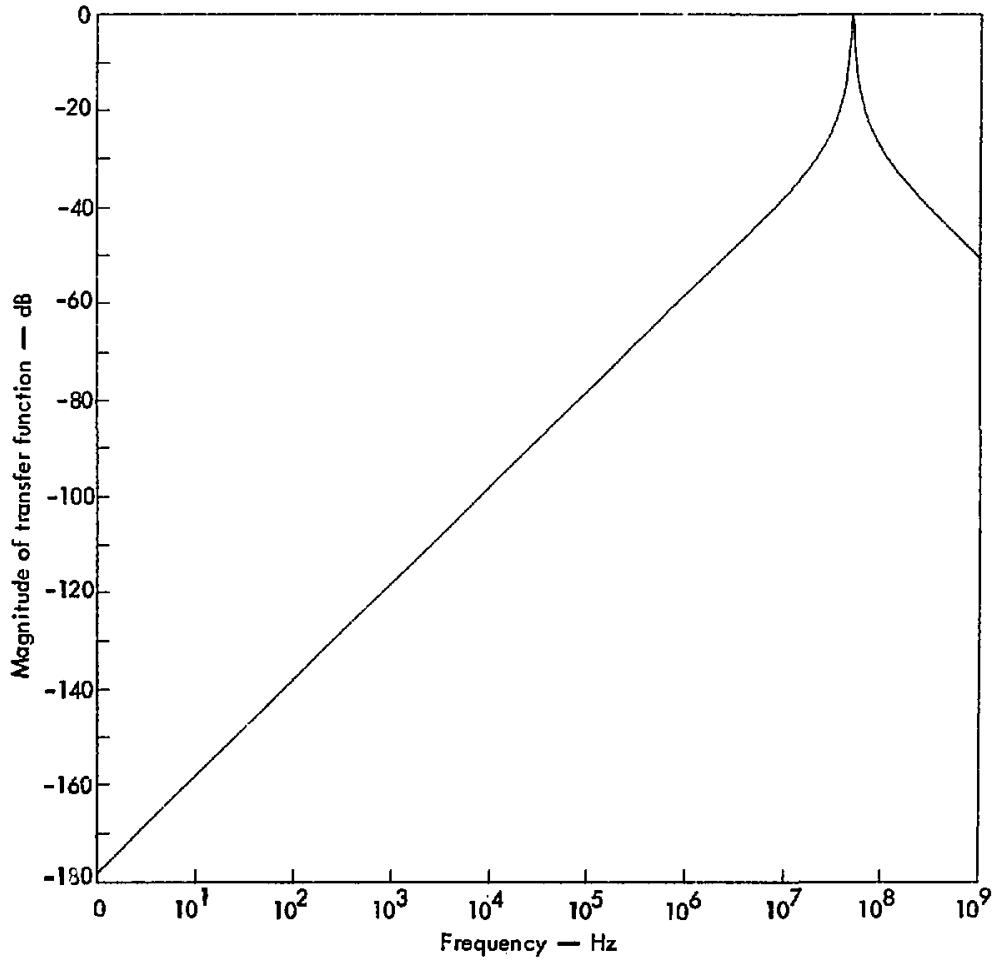

FIg. 1. Magnltude of the transfer function in decibels for the single re...".nt case. 


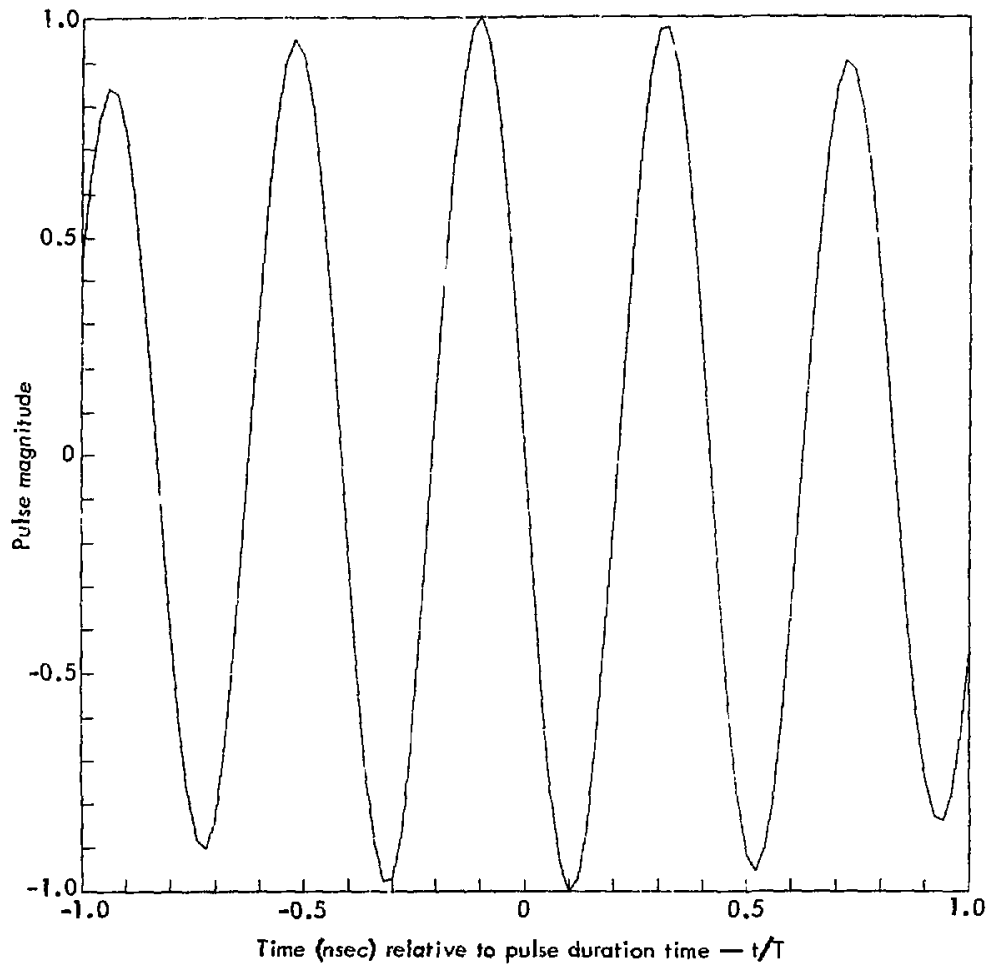

F1g. 2. Optimum pulse for the case where $T=50$ nsec. Maximum eigenvalue $=0.35$.

The reason for the cholce was to attempt to match some numerical transfer function data for a long, narrow slot in an infinite ground plane. The resulting optimum pulse for the case $\mathrm{T}=50 \mathrm{nsec}$ (Fig. 2) is a modulated signal whose period corresponds to the frequency of the resonance of the transfer function. When $T=100 \mathrm{nsec}$ (Fig, 3), the period of the ripple stays the same but the decay of the envelope is more pronounced. In 
addition the elgenvalue has increased from 0.35 to 0.54 which indicates a strong increase in energy transfer efficlency. When $T$ is increased to $200 \mathrm{nsec}$ (FIg. 4) and then to $300 \mathrm{ngec}$ (Fig. 5), the modulation frequency remains the same but the envelope decay continues to increase. In addition, the eigenvalue 1ncreases to 0.68 and then to 0.74 .

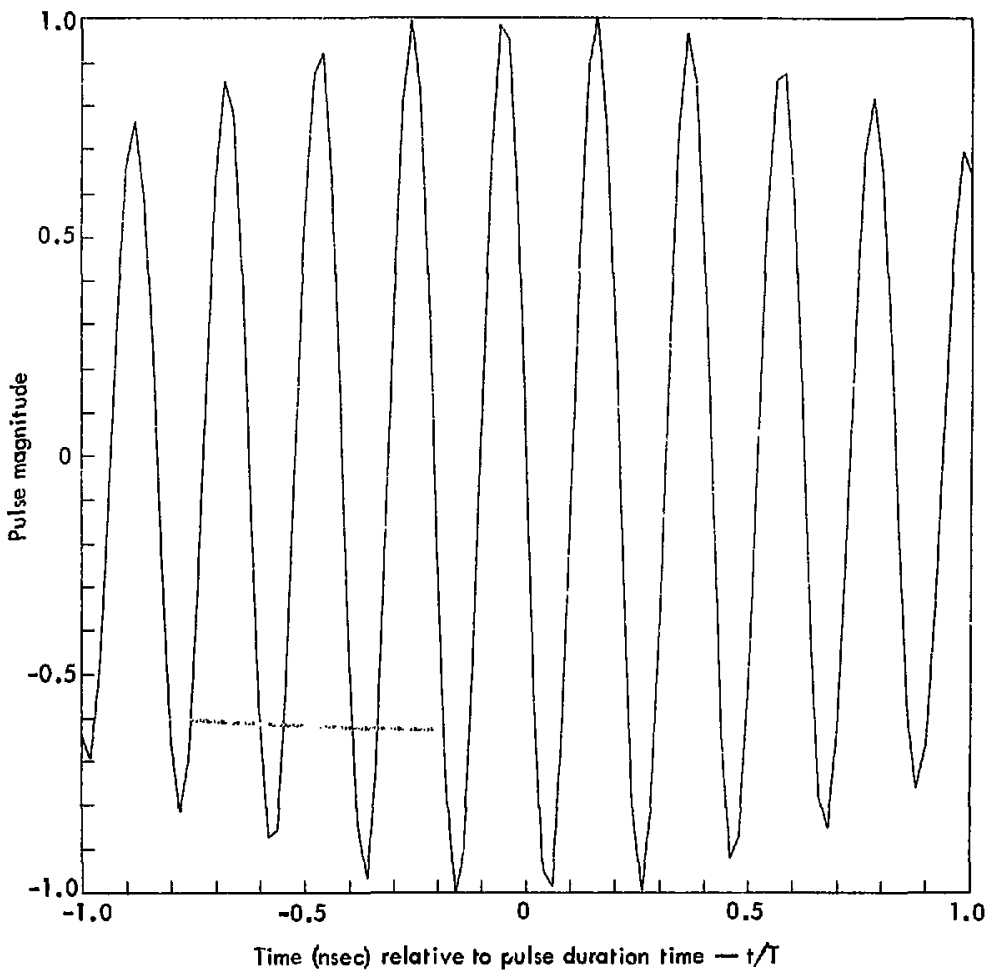

F1g. 3. Optimum pulse for the case where $T=100$ nsec. Maximum elgenvalue $=0.54$. 


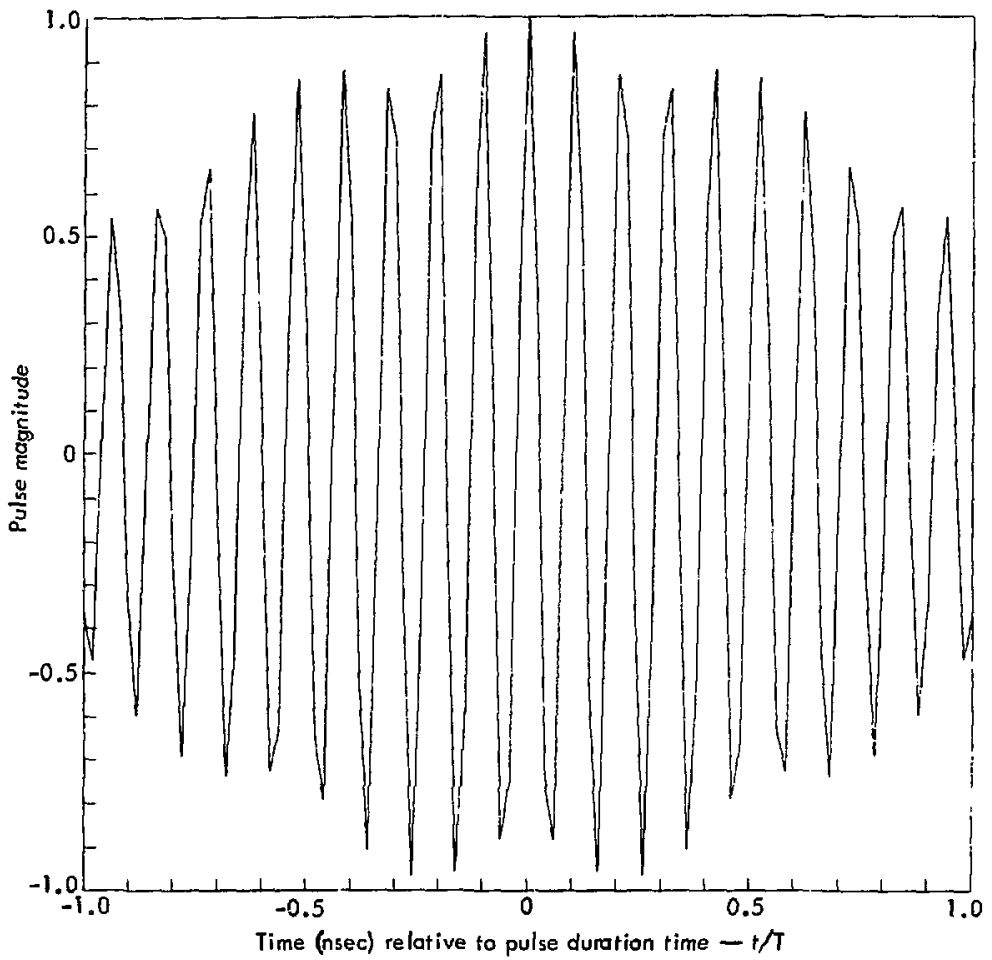

F1g. 4. OptImum pulse for the case where $T=200$ nsec. Maximum eigenvalue $=0.68$ 


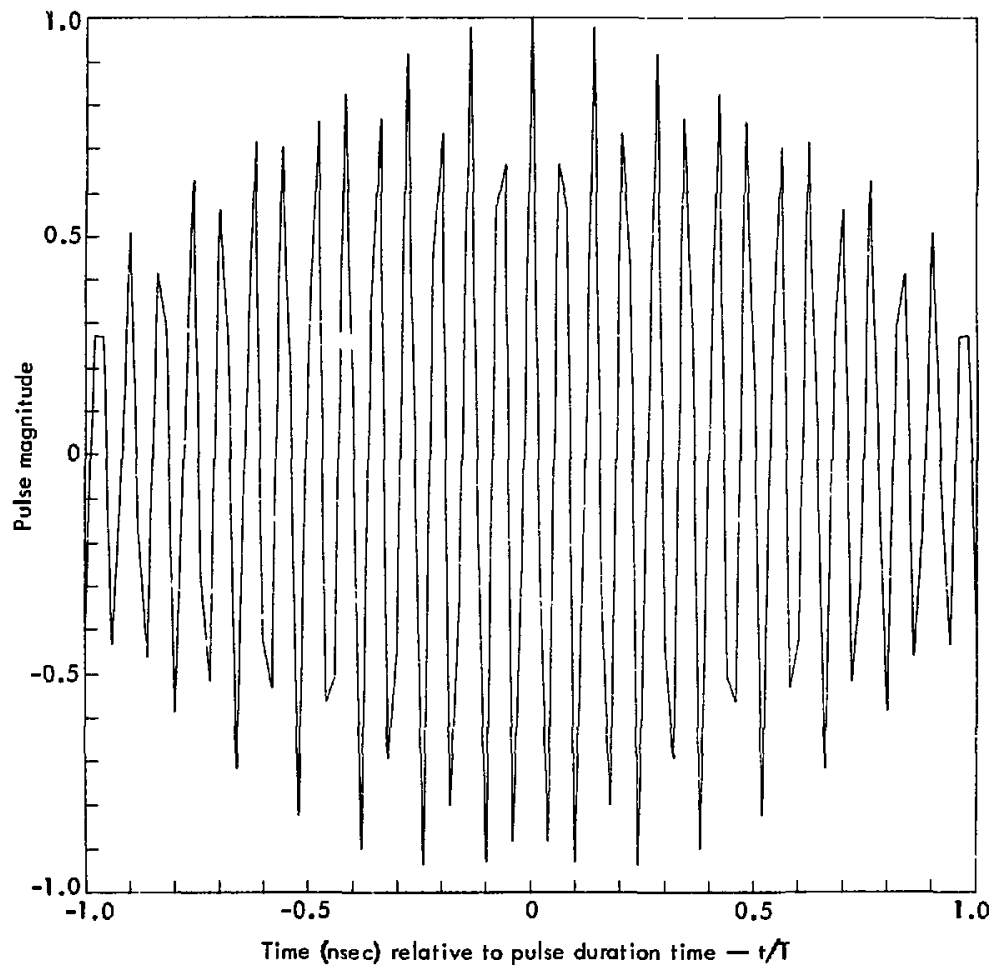

Fig. 5. Optimum pulse for the case where $T=300$ nsec. Maximum elgenvalue $\square 0.74$.

Conclusions and Recommendations for Further Work

There are few ourprises in the numerical results for the single resonance case. The optlmum pulse contains a modulation rate which favora the frequency at which the transfer function has its peak. In addition the pulse becomes more efficient as the length of time $(-T, T)$ of application 
of the incident pulse is increased. The shape of the envelope is qualitatively similar to the shape of the entire pulse for the low-pass filter investfgated by Chalk and by Slepian and Pollak. This is in keeping with the ideas common in equivalent low-pass filter analysis of band-pass filters (Ref, 4, p. 122). (Here, we regard the single-resonant model us a band-pass filter.)

We noted earlier that the results are only preliminary. However, now that the computer program has been written, a large range of transfer functions can be investigated. Such an investigation should produce some trends in the transfer of energy which should make possible some generalizations concerning the process.

In addition, there seems to be no fundamental limitation on the infinite limits in the integral of Eq. (6). If the limits were finite, the analysis would proceed as before with the exception that the kernal function in Eq. (10) would be calculated from an integral over fintte 11mits. This is an important observation because tt raises the possibility of maximizing the energy in a finite bandwidth in the output to the inear system. Fortunately, if we agree to add the energy contribution in the finite bandwidth $\left(\omega_{1}, \omega_{2}\right)$ and the energy in the same band over the mirror negative frequencles, the symmetry of the kernal function is not destroyed and we may proceed with the numerical reduction as before. 


\section{References}

1. J. H. H. Chalk, "The Optimum Pulse-Shape for Pulse Communication," Proc. Inst. Elec. Engrs, (London) 87, 88 (1.950).

2. D. Slepian and H. O. Pollak, "Prolace Spheroldal Wave Functions, Fourter Analysis and Uncertalnty - I," BelZ System Tech. J. 40 (1), 43 (1961).

3. C. Flammer, Spheroidat Wave Funotions, (Stanford Universtty Press, Stanfurd, 1957).

4. A. Papoul1s, The Eourier Integral and its Applications (McGraw-H111 Co., New York, 1962), p. 27.

5. G. Arfken, Hathematical Methods for Physicisto (Academlc Press, New York, 1966), Pp. 593-597.

6. R. F. Harrington, Fieid Computations by Moment Methods (Macmlllan, New York, 1968).

7. R. P. Dickinson, F. N. Fritsch, R. F. Hausman, and R. F. Sincovec, EISPACK ISer's Guide, Lawrence Livermore Laboratory, Rept. UCID-30077 (1973).

8. D. G. Dudley, Numerical Inversion of the Founier Transform, A Combination Trapezoidat and Fiton Technique, Lawrence Lfvermore Laboratory, Rept. UCRL-51878 (1975). 
Appendix A - Maximization with a Constraint 
We wish to maxtmize the dauble integral

$$
E_{0}=\int_{-T}^{T} f(\tau) \int_{-T}^{T} f(x) K(|x-\tau|) d x d \tau
$$

subject to the constraint

$$
E_{I}=\int_{-T}^{T} f^{2}(t) d t
$$

We form the functional $\mathrm{E}(\mathrm{f})$

$$
E=E_{0}-\lambda E_{I} \text {, }
$$

where $\lambda$ is a Lagrange multiplier. We therefore have

$E=\int_{-T}^{T} f(\tau) \int_{-T}^{T} f(x) k(|x-\tau|) d x d \tau-\lambda \int_{-T}^{T} f^{2}(t) d t$.

Let \& take on a varlation $\delta$ so that

$$
\begin{aligned}
E(f+a \delta)=\int_{-T}^{T}[f(\tau)+\alpha \delta(\tau)] & \int_{-T}^{T}[f(x)+\alpha \delta(x)] K(|x-\tau|) d x d \tau \\
& -\alpha \int_{-T}^{T}[f(x)+\alpha \delta(x)]^{2} d x \cdot(A-5)
\end{aligned}
$$

Expanding and collecting terms, we cbtain

$$
E(\varepsilon+\alpha \delta)=E(f)+2 \alpha C+\alpha^{2} H-2 \alpha \lambda I-\alpha^{2} \lambda J,
$$

where

$$
G=\int_{-T}^{T} \delta(\tau) \int_{-T}^{T} f(x) x(|x-\tau|) d x d \tau
$$




$$
\begin{aligned}
& H=\int_{-T}^{T} \delta(\tau) \int_{-T}^{T} \delta(x) K(|x-\tau|) d x d \tau \\
& I=\int_{-T}^{T} f(x) \delta(x) d x \\
& J=\int_{-T}^{T} \delta^{2}(x) d x .
\end{aligned}
$$

To maximize (or minimize), take

$$
\left.\frac{\partial}{\partial \alpha}[E(E+\alpha \delta)]\right|_{\alpha=0}=0
$$

with the result

$$
G=\lambda I,
$$

or,

$$
\int_{-T}^{T} \delta(\tau) \int_{-T}^{T} f(x) k(|x-\tau|) d x d \tau=\lambda \int_{-T}^{T} \delta(\tau) .
$$

This may be written

$$
\int_{-T}^{T} \delta(\tau)\left\{\left[\int_{-T}^{T} f(x) K(|x-\tau|) d x\right]-\lambda f(\tau)\right\} d \tau=0 \quad(A-14)
$$

and since $\delta$ is arbirrary

$$
\lambda f(\tau)=\int_{-T}^{T} f(x) k(|x-\tau|) d x .
$$

which is a vertfication of Eq. (11). 
Appendix B - Computer Program Listing 


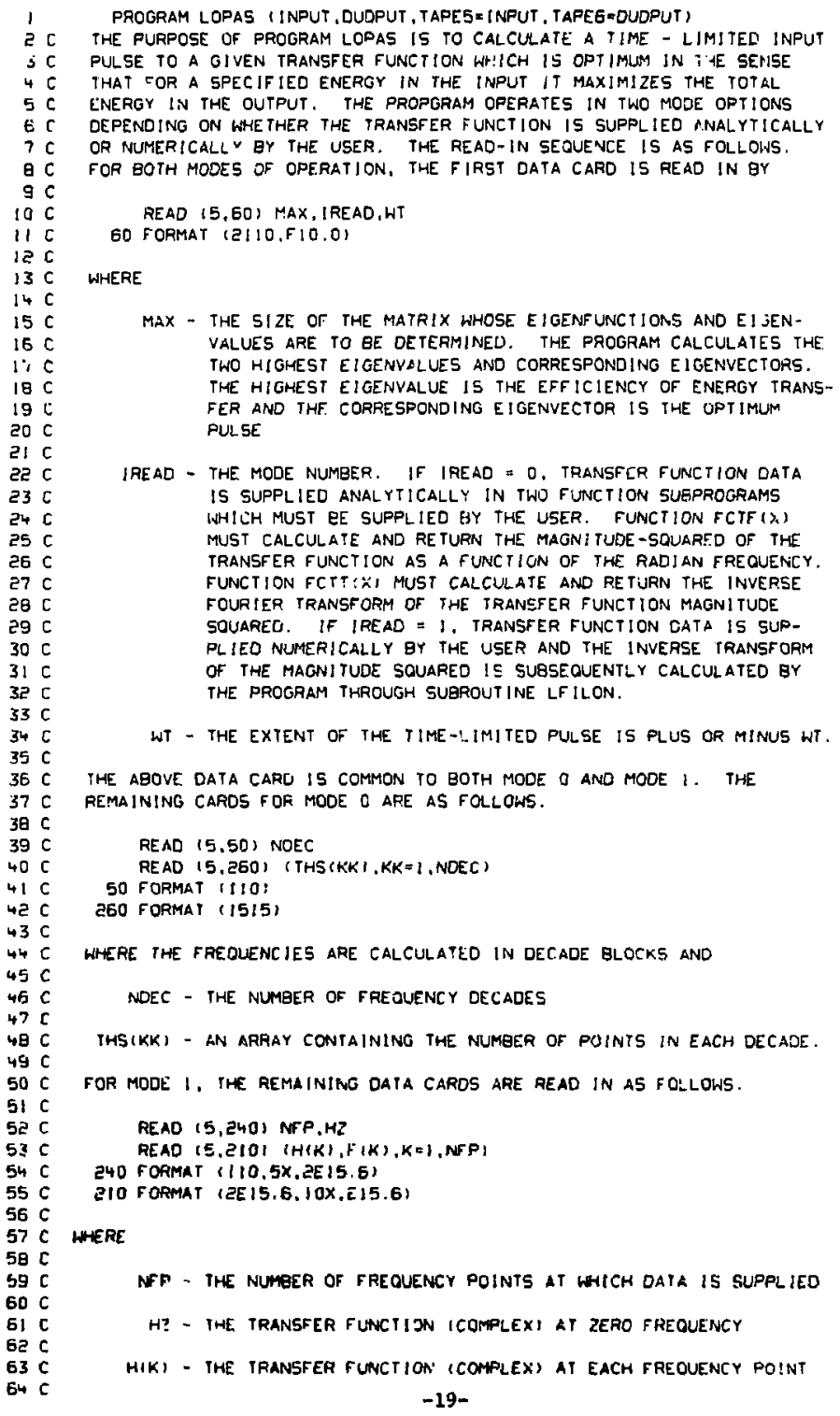

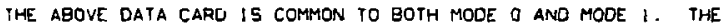
REMAINING CAROS FOF MODE O ARE AS FOLLOWS.

READ (5.50) NOEC

READ 15,260 ) (THS (KK),KK=1, NDEC)

50 FORMAT IIIO:

260 FORMAT (1515)

WHERE THE FREOUENCIES aRe CALCULATEO IN DECADE BLOCKS AND

NOEC - THE NUMBER OF FREOUENCY OECADES

IHSIKK) - AN ARRAY CONTAINING THE NUMEER OF POINTS IN EACH DECADE.

FOR MODE 1, IHE REMAINING DATA CAROS ARE READ IN A5 FOLLOWS.

READ $(5,240)$ NFP. HZ

READ (E.ZIO) (H(K),F(K),K=1,NF)

240 FORMAT $(110.5 \times$. $2 E$ (5.5)

EIO FORMAT (EE I5.6.10X.E15.6)

HERE 


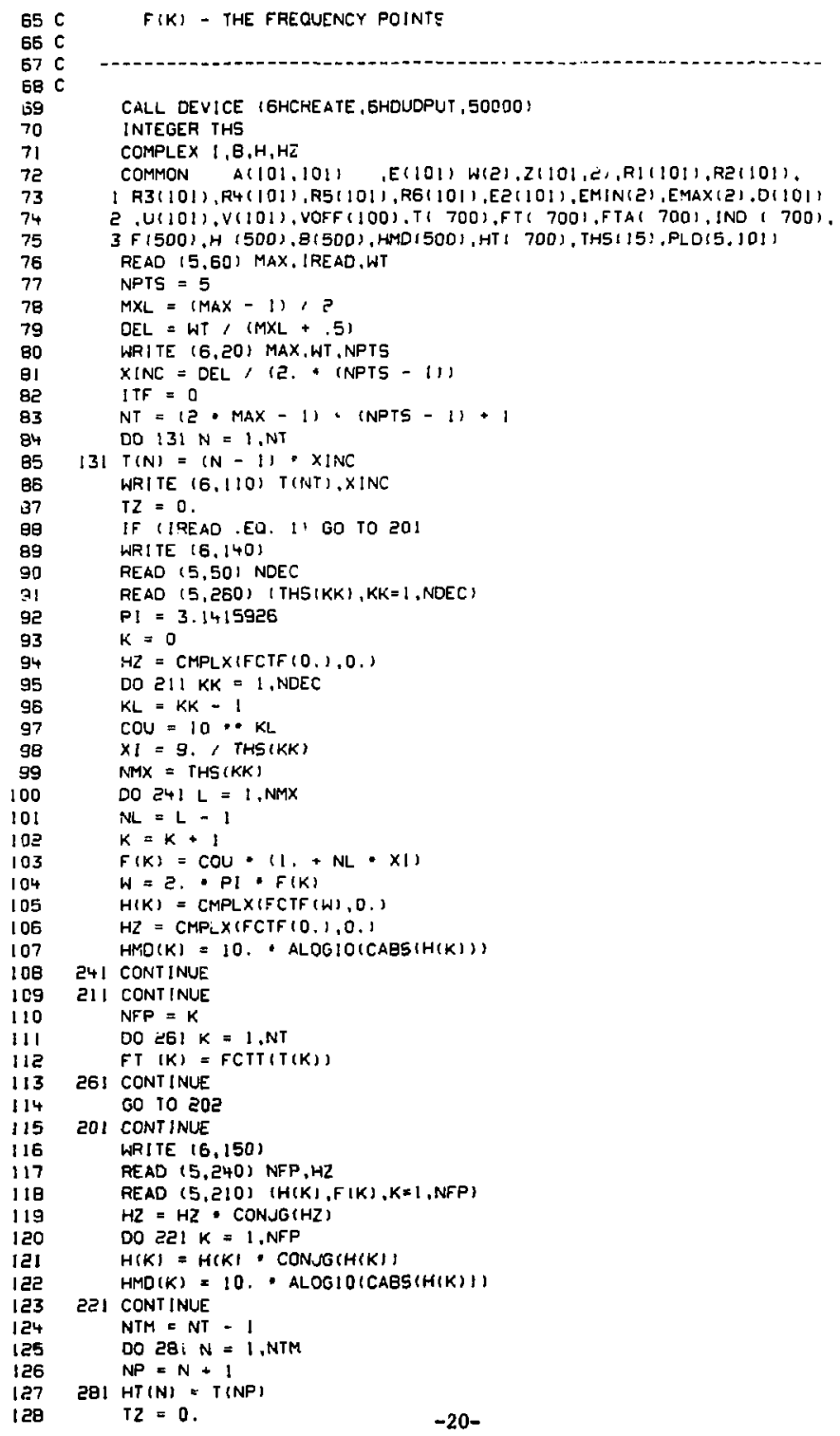

CALL DEVICE 16HCHEATE, EHOUDPUT, 50000:

INTEGER THS

COMPLEX $\quad \mathrm{I}, \mathrm{B}, \mathrm{H}, \mathrm{H} \overline{\mathrm{Z}}$

COMMON A(I01.101) ,E(101) W(2).Z1101,L),RI(101),R21101).

I R3(101),R4(101), R511011,R61101),E2(101),EMIN(2), EMAXI(2), DI101) 2, U(101), V(101), VOFF(100),T1 700),FT( 7001,FTAI 7001, INO 1700$)$, 3 F $(500), H(500), B(500)$, HMD 500$), H T) 700)$, THS 1 15), PLO $(5,10\})$

READ 15.60) MAX.IREAD.WT

NPTS $=5$

$M X L=(\operatorname{MAX}-1), ?$

$O E L=W T,(M X L+.5)$

WRITE (6,20) MAX,WT, NPTS

$X I N C=D E L,(2 . * 1 N P T S-11)$

ITF $=0$

NT $=(2 \cdot \operatorname{MAX}-1) \cdot(N P T S-1)+1$

DO $131 \mathrm{~N}=1 . \mathrm{NT}$

$131 T(N)=(N-1) \cdot X I N C$

WRI TE $(6,110)$ T(NT), XINC

$T Z=0$.

IF IIREAO .EO. I' GO TO 201

WR! TE $(6,140)$

REAO $(5,50)$ NDEC

REAO $(5,260)$ (TH5 $(K K), K K=1$, NOEC)

$P !=3.1415926$

$K=0$

$H Z=C M P L X(F C T F(0), 0$.

DO $21 ! K K=1$, NDEC

$K L=K K-1$

$\operatorname{cov}=10 \cdots \mathrm{KL}$

$x_{l}=9 ., T H S(K K)$

NMX = THS $(K K)$

DO $241 \mathrm{~L}=1, \mathrm{NMX}$

$N L=L-1$

$k=k+1$

$F(K)=\operatorname{COU} *(1,+N L \cdot X 1)$

$W=2 . P I \cdot F(K)$

$H(K)=C M P L X(F C T F(W), 0$,

$H Z=$ CMPLX $(F C T F(0,1,0,1$

$H M D(K)=10$. ALOG $10(C A B S(H(K))$

24I CONTINUE

EII CONTINUE

NFP $=K$

DO $26 ! K=1, N T$

$F T(K)=F C T T(T(K))$

26! CONTINUE

GO 10 20D

201 CONT INUE

WRITE $(6,150)$

READ $(5,240)$ NFP, HZ

READ $(5,210)$ (H(K), F (K), K=1, NFP)

$H Z=H Z \cdot C O N J G(H Z)$

DO 22! $K=1, N F P$

$H(K)=H(K) \cdot$ CONUGrH(K)

$H M D(K)=10$. ALOQ10(CABS(H(K))

2दI CONTINUE

NTM = NT - 1

Do 28: $N=1, N T M$

$N P=N+1$

$281 H T(N) \approx T(N P)$

$T Z=0$. 


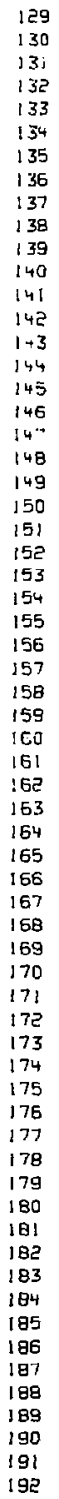




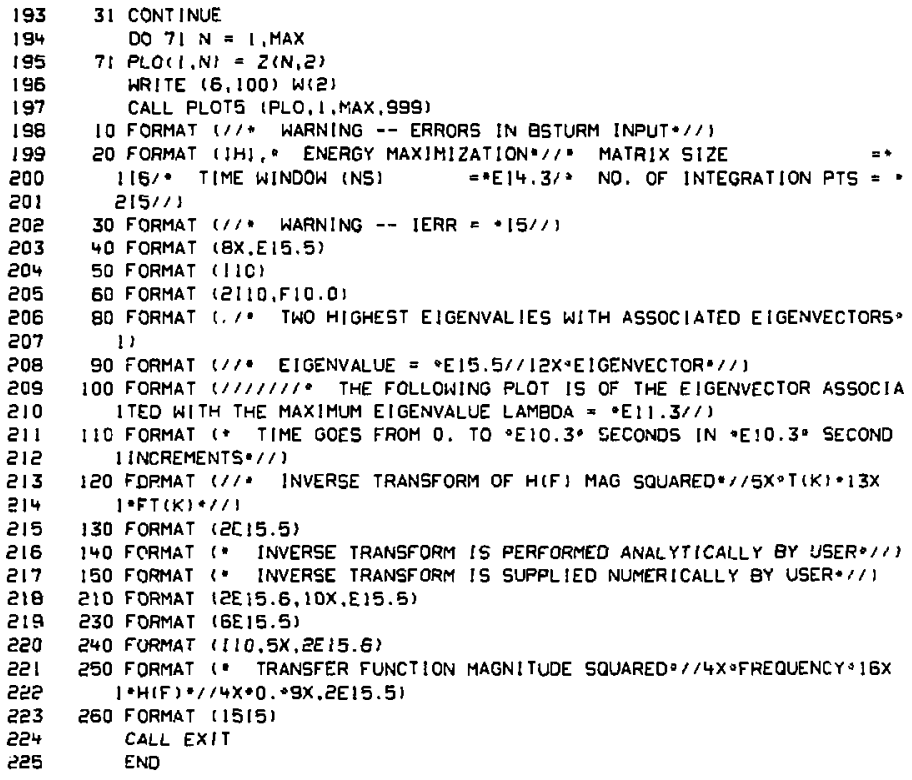




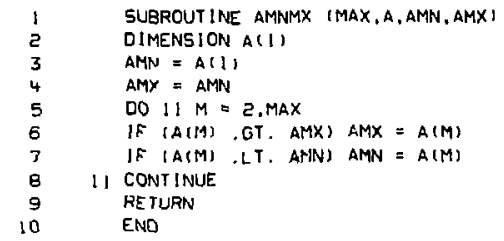




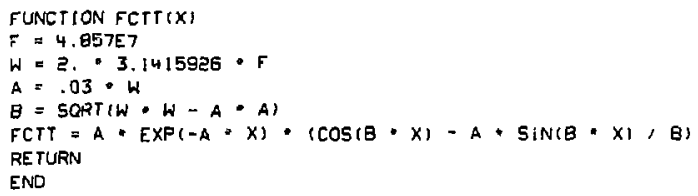




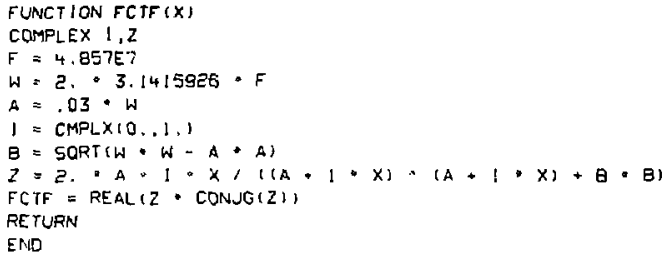


SUEROUT INE TSTURMINH, N,EPSI, D,E,EZ,LE, UB, MM, M, W, Z,

93215004 $x$ IERR,RVI, RVE, RV3, RV4, RVS,RV6I

93215005

\section{C.NMS : MATHL IE: NATS :E ISPACK : SOURCE : ISTURM \\ TSTURM ER.VR 11 /2OST3 LLLE}

INTEGER $1, J, K, M, N, P, O, R, S, I 1, I P, J U, M M, P I, M E, N M, I T S$,

93215006

$X \quad$ IERR,GROUP, ISTURM

93215007

REAL D(N),E(N),EZ(N),W(MM), Z(NM, MM).

10

$X$

$R V I(N), R V E(N), R V 3(N), R V 4(N), R V 5(N), R V E(N)$

9321500 A

93215009

93215010

93215011

9321501 ?

LLLESO I3

9321501 .

93215015

93215016

93215017

93215018

93215019

93215020

9321502:

93215022

93215023

93215024

93215025

93215026

93215027

932150?8

93215029

93215030

93215031

93215032

93215033

$932 ! 5034$

93215035

93215036

93215037

$932: 5030$

93215039

93215040

93215041

93215042

9.215043

93215044

93215045

93215046

93215047

93215048

93215049

93215050

93215051

93215052

93215053

93215054

93215055

93215056

93215057

93215058

93215059

93215060

93215061

93215062

93215063 


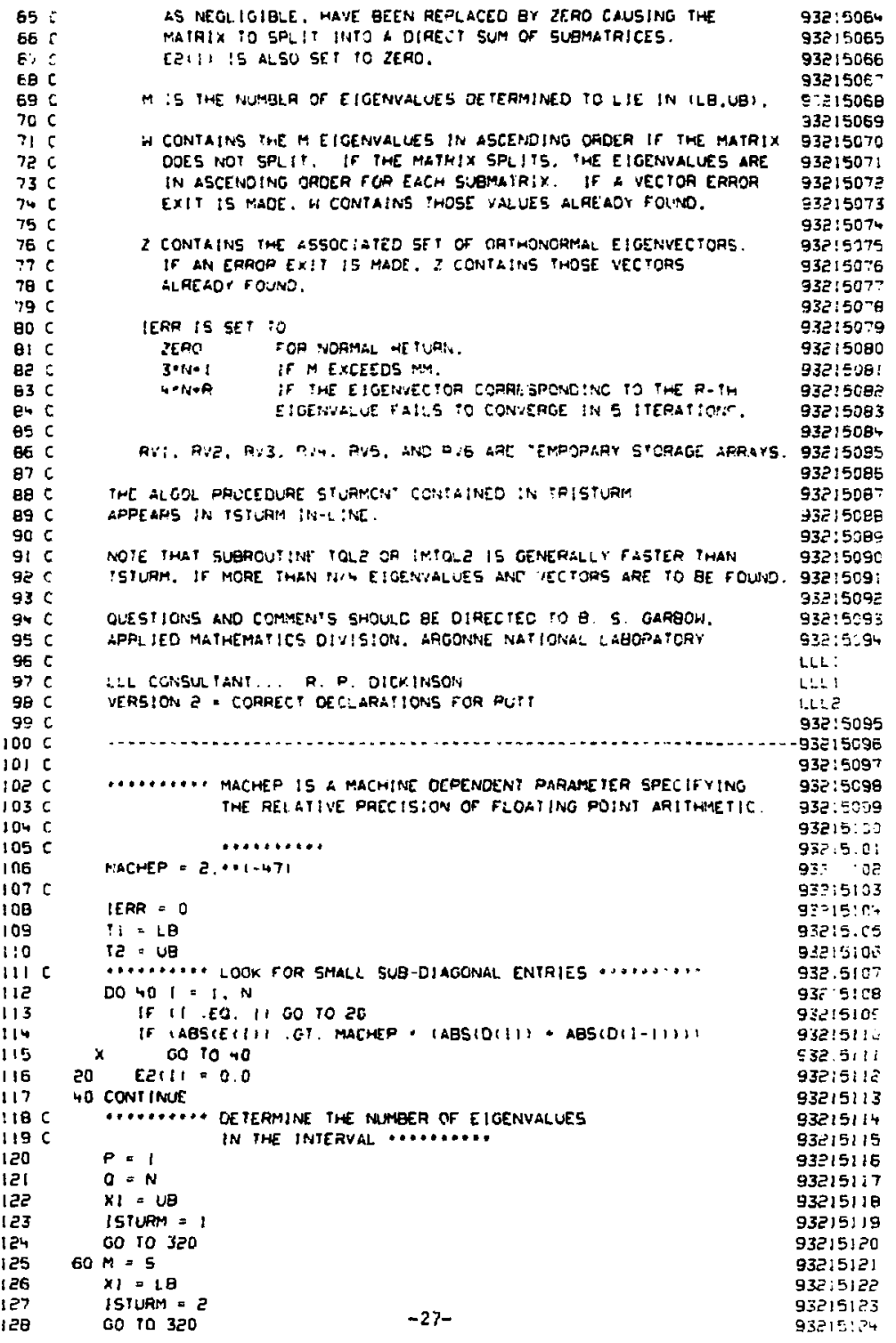




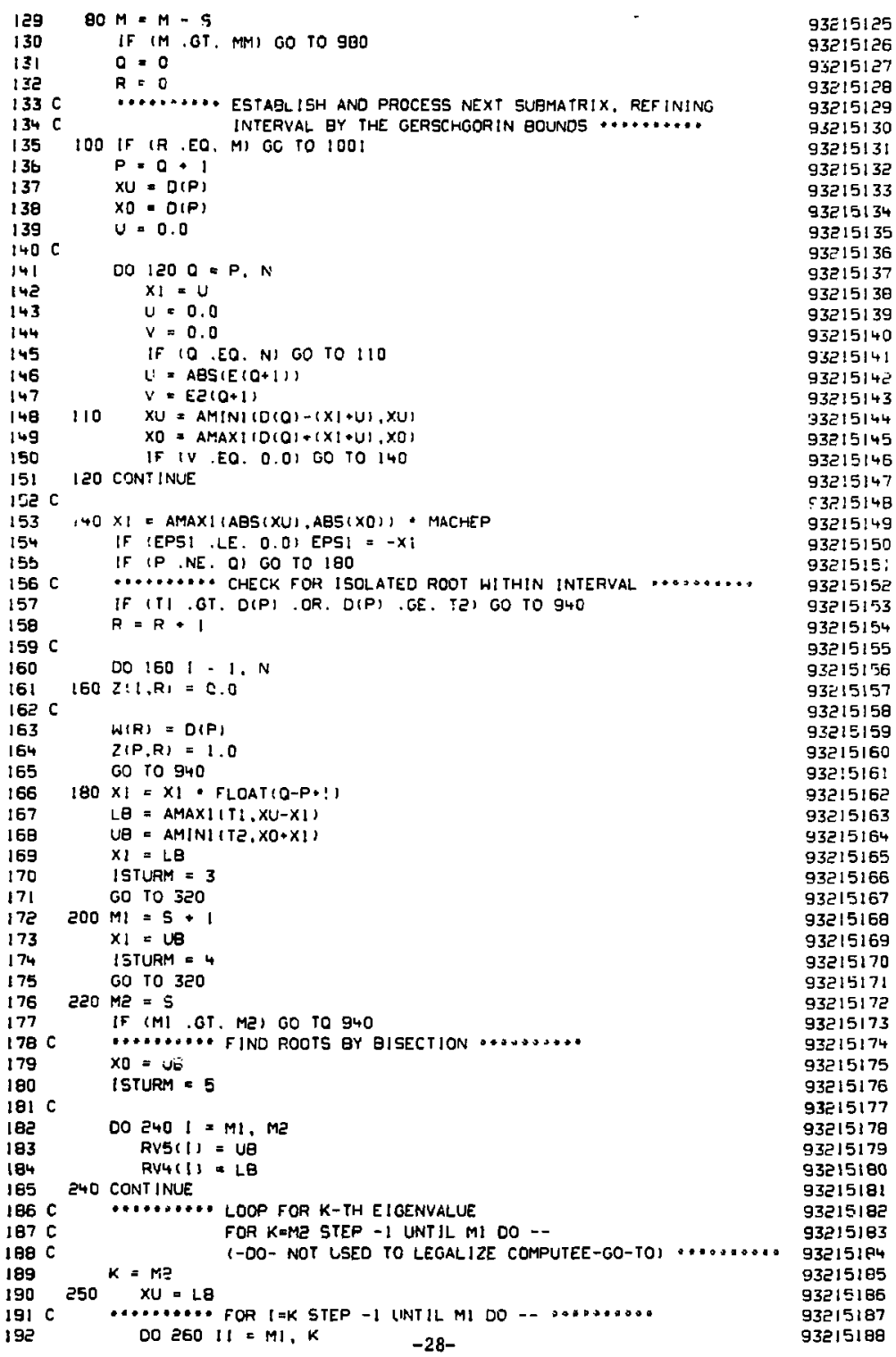




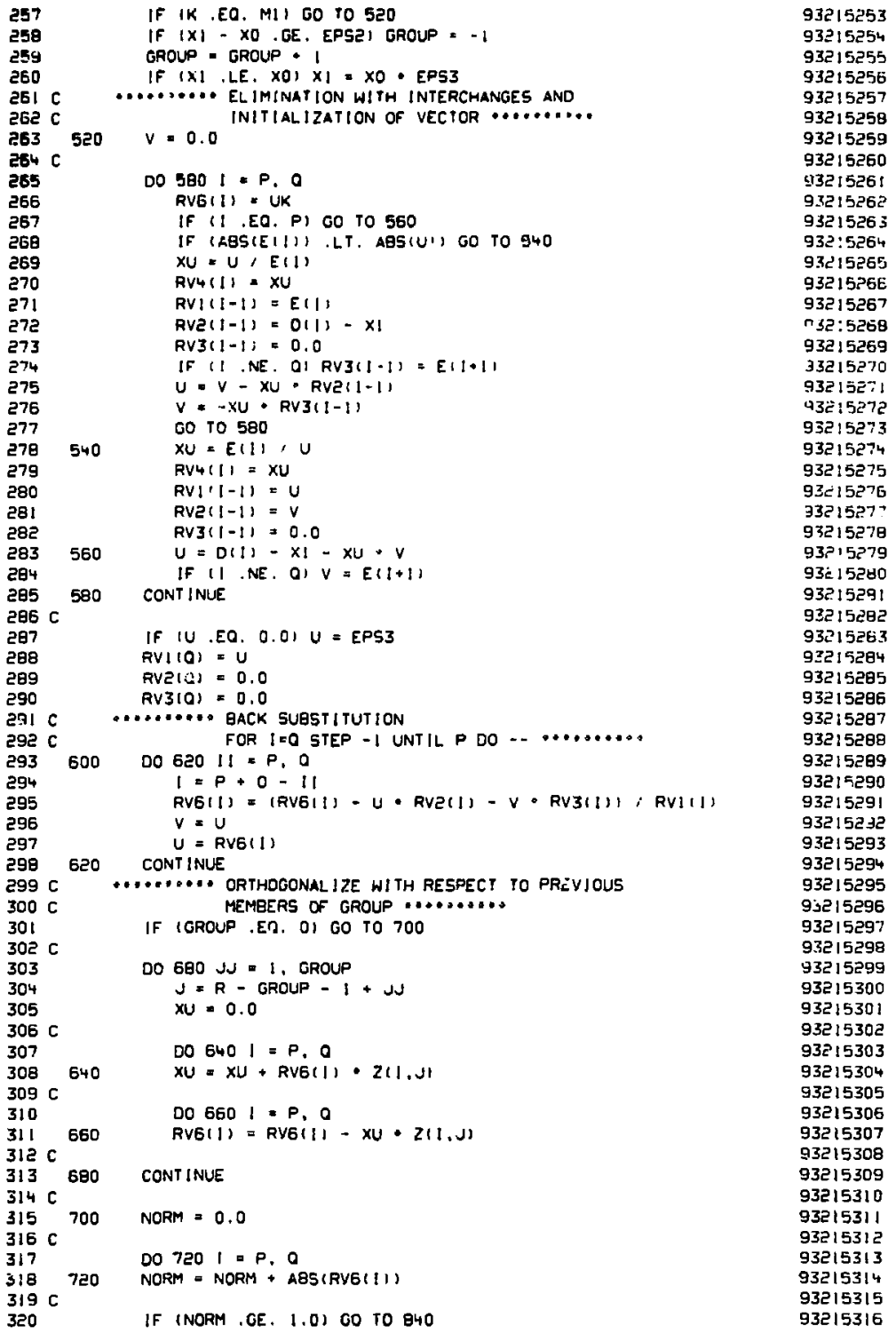




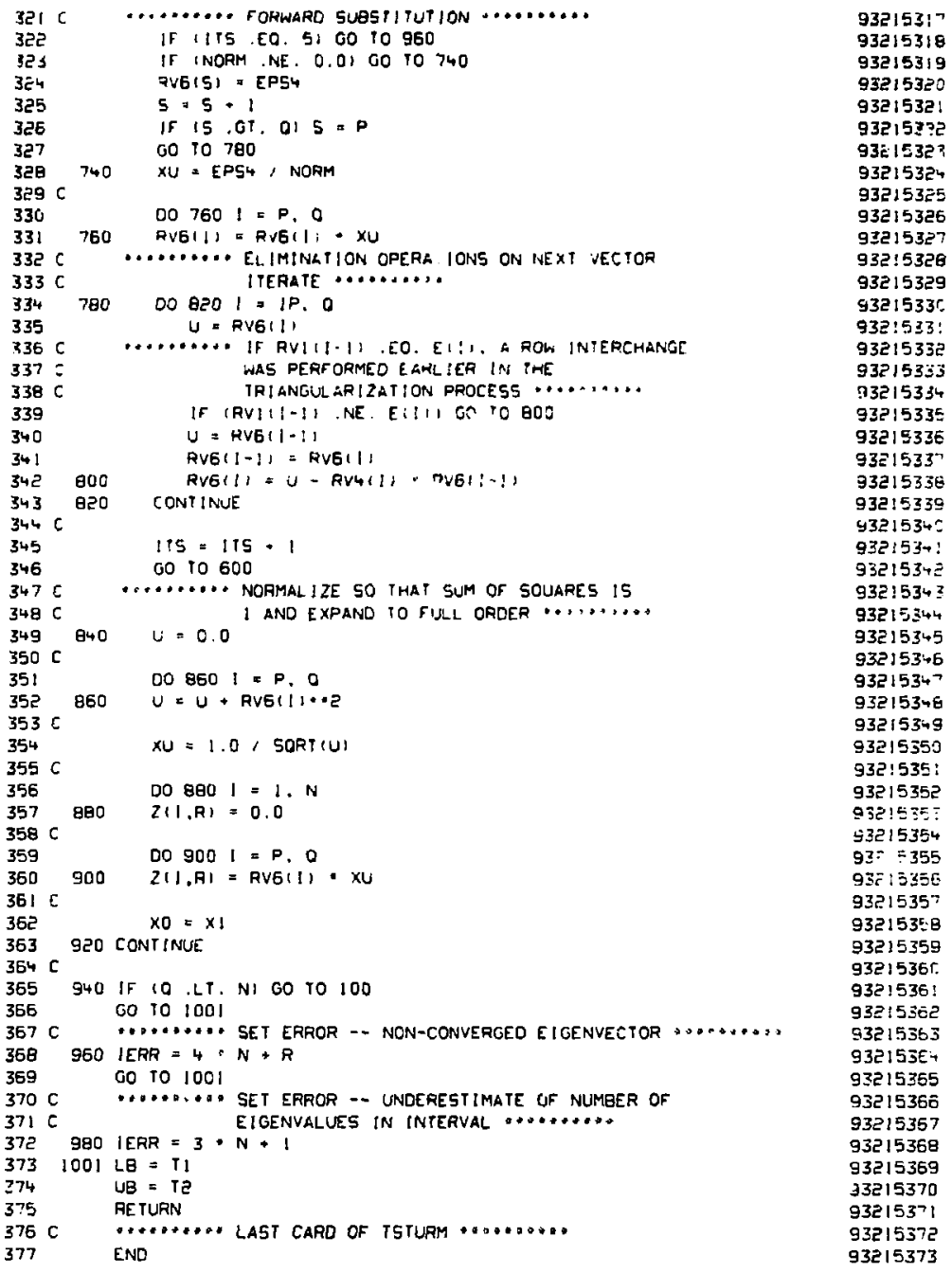


77215069

$5 \mathrm{C}$

77215070

7721507 !

77215072

$F=A 11.6)$

$G$ a -SIGNISQRT(H), F)

77215073

$772: 5074$

EII I = SCALE * $G$

77215075

$H=M-F=G$

$7 ? 5156 ? 6$

$A(l, k)=F-G$

77215077

IF IL EO. Ij 00 TO 270

77215078

$F=0.0$

77215079

77215080

$00240 \mathrm{~J}=1.1$

$0=0.0$

73215081

77215062

77215083

77215084

$772 ! 5085$

DO $1 B 0 \mathrm{~K}=1 . \mathrm{J}$

$89180 \quad G=G \cdot A(J, k) \cdot \hbar 11, k ;$

77215086

77215087

$J P !=J \rightarrow 1$

91

92

$93 \mathrm{C}$

IF IL LT. JPII GO TO 250

77215080

77215099

$94 \quad 00200 K=J P 1, L$

$95200 \quad G=G+A(K, J) \cdot A(l, k)$

77215090

77215091

77215092

$772 ! 5093$

77215094

77215095

77215096

77215097

77215098

77215099

?7215100

7?2!E10!

$7 \because 215102$

77215103

$7721510^{4}$

$00260 k=1 . J$ $A(J, K)=R(J, K)-F \cdot E(K)-G \cdot A(I, K)$

109

110

ill $\mathrm{C}$

260 CONTINUE

77215105

77215106

77215107

77215108

77215109

113 2BO $A(1, K)=$ JCALE, A(1,K)

$114 \mathrm{C}$

$115290 \quad H=D(1)$

$116 \quad$ QI $)=A(\{.1)$

$117 \quad A(1,1)=\mathrm{H}$

1 1 300 CONTINUE

$119 \mathrm{C}$

120 RETURN

IE! C $\because \ldots \ldots \ldots+$ LAST CARD OF TREDI

122

END

77215110

77215111

77215112

77215113

77215114

77215115

77215116

77215117

77215118 
REAL DINII,EINII,EEINI)

I.LL 140

BSTU 140

BSTU 150

TH!S SUBROUTINE CAN ALSO BE USED TO EVALUATE THE STURM COUNT FOR BSTU IGO ANY REAL NUMBER, WHERE THE STURM COLNT IS THE NUMBER OF BSTU ITO EIGENVALUES, COUNTINO MULTIPLICITIES, STRICTLY TO THE LEFT OF THE BSTU IBO OIVEN INPUT NUMBER.

BSTU 190

BSTU 200

BSTURM WAS DESIGNED TO SUPPLEMENT THE EISPACK PACKAGE.

TH!S SUBROUTINE WAS WRITTEN AT LAWRENCE LIVERMORE LABORATORY

BSTU $5 I 0$

DIRING AUGUSI 1973 BY ROBERT DICKINSON OF N.M.S.

BSTU 550

ON INPUT :

NI IS THE ORDER OF THE MATRIX A.

ESTU 230

BSTU ट̇廿

KI IS THE NUMBER OF EXTREME EIGENYALUES DESIRED. IF IFLAG IS Z BSTU 310 OR 3 .

IFLAG MAY HAVE THREE VALUES.

IF IFLAG IS \& THE USER WANTS THE STURM COUNT AT THE INPUT VALUE XL.

IF IFLAG IS 2 THE USER WANTS AN IINTERVAL WHICH CONTAINS THE KI SMALLEST EIGENVALUES OF A.

IF IFLAG IS 3 THE USER WANTS AN INTERVAL WHICH CONTAINS THE KI LARGEST EIGENVALUES OF A.

$X L$ IS AN INPUT NUMBER IF IFLAG IS I, AND IN THIS CASE THE. NUMBER OF EIGENYALUES, COUNTING MULTIPLICITIES, STRICTLY TO THE LEFT OF XL IS TO BE CDMPUTED.

D IS A LINEAF ARRAY OF DIMENSION NI WHICH CONTAINS THE DIAGCNAL ELEMENTS OF A. DIII=A(I, I) FOR $i=1$ THROUGH NI.

E IS A LINEAR ARRAY OF DIMENSION NI WHICH CONTAINS THE SUBDIAGONAL ELEMENTS OF $A, E(1)=0$. AND $E(1)=A(1, i-1) F C R$ $1=2$ THROUGH N!.

BSTU 260

BSTU 270

HSTU 290

BSTU 290

BSTU 320

BSTU 330

BSTU 340

BSTU 350

BSTU 360

BSTU 370

ESTU 390

BSTU 390

BSTU 400

BSTU 410 BSTU 420 BSTU 430 BSTU 440 BSTU 450

BSTU 460 BSTU 470 BStu 480 BSTu 490 SSTU 500 BSTU 510 BSTU 520

E2 IS A LINEAR ARRAY OF DIMENSION N1 WHICH CONTAINS THE SQUARESBSTU 5.30 OF ELEIENTS OF THE E ARRAY. THAT IS EZ(I)=EII]*EII) FOR i=! BSTU 540 THROUGH NI.

BSTU $\mathbf{5 5 0}$

BSTU 560

ON OUTPUT:

XL AND XU ARE THE LOWER AND UPPER ENDPOINTS, RESPECTIVELY, OS THE DFSIRED INTERVAL IF THE INPUT VALUE OF IFLAG IS 2 OR 3.

\section{BSTU 580}

BSTU 590 BSTU 600 BSTU 610

ICI IS THE STURM COUNT IF THE INPUT VALUE OF IFLAG IS 1.

ICl IS THE NUMBER OF EIGENVALUES IN THE INTERVAL IF THE INPUT 


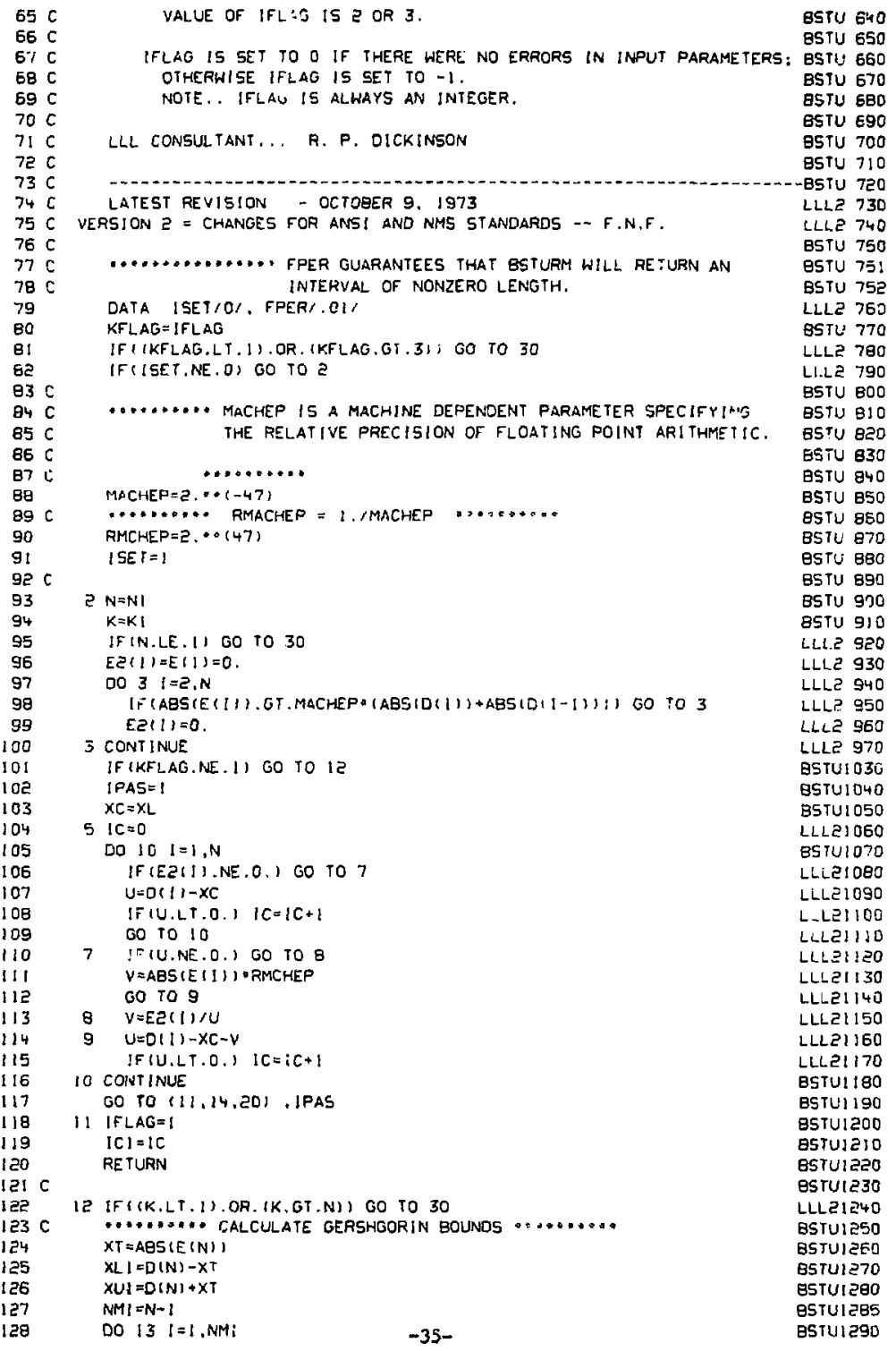


150

$15 ! \mathrm{C}$

$17 X(1=A M A X 1(X U 1+F P E R=A B S(X U 1)$, FPER $)$

EPS! - AMAXI (ABS $(X L 1)$, ABS IXU) I M MACHEP

ITEST $=N-K$

IF $[(N-[C] . L T, K)$ GO TO 19

$X L=X U I$

$I C I=N-I C$

RE TURN

19 $X C=1 \times L)+X U 1) \cdot .5$

60 TO 5

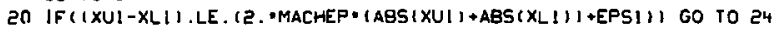
IF. IC.LE. ITESTI GO TO 22

$X U I=X C$

$I C J=1 C$

GO 1019

a2 IFIIC.GE. ITEST! GO TO $2 ?$

$X_{L} I=X C$

$1 C L=I C$

GO 1019

24 IF IKFLAG.NE.EI GO TO 26

$X U=X U !$

$|C|=! C u$

RETURN

$26 \times L=X L 1$

ICI $=\mathrm{N}-1 \mathrm{CL}$

RETURN

27 IF (KFI_AG.NE. E) GO TO 29

$X U=X C$

$|C|=\mid C$

RE TURN

C

$29 \times L=X C$

$|C|=\mathrm{N}-\mid \mathrm{C}$

RETURN

30 IFLAG $=-1$

RETIRNN

BSTU1360

BSTU1370

BSTUI 380

LLLE 1390

BSTU1400

BSTUI410

BSTUI420

BSTU1 130

L'LLI I 40

LLL21450

BSTU1 455

BSTU1460

LLLP1470

LLL21480

BSTU1490

BSTU1500

BSTU1510

BSTU1520

BSTU1525

BSTU1530

LLL21540

LLL21550

gSTU1550

BSTU1570

BSTUI580

gSTUI590

BSTUI600

BSTU1610

LLLC16?0

LLLP1630

BSTUI640

BSTU1650

LLL2 I660

LLLP!670

BSTU1680

BSTUI690

LLLE1700

LLLP 1710

ESTU1720

BSTU1730

BSTU1740

ESTU1750

BSTU1760

ESTU) 770

B5TUI 780

LLLEI 790

LLLe1800

BSTU1810

BSTUIB20

ESTUIB30

BSTU1840

BSTUI850

BSTUI860

BSTU1B70

BSTUIBBO

gSTU1890

BSTUI900

BSTUI9IO 
I END

BSTU1920

$-37-$ 


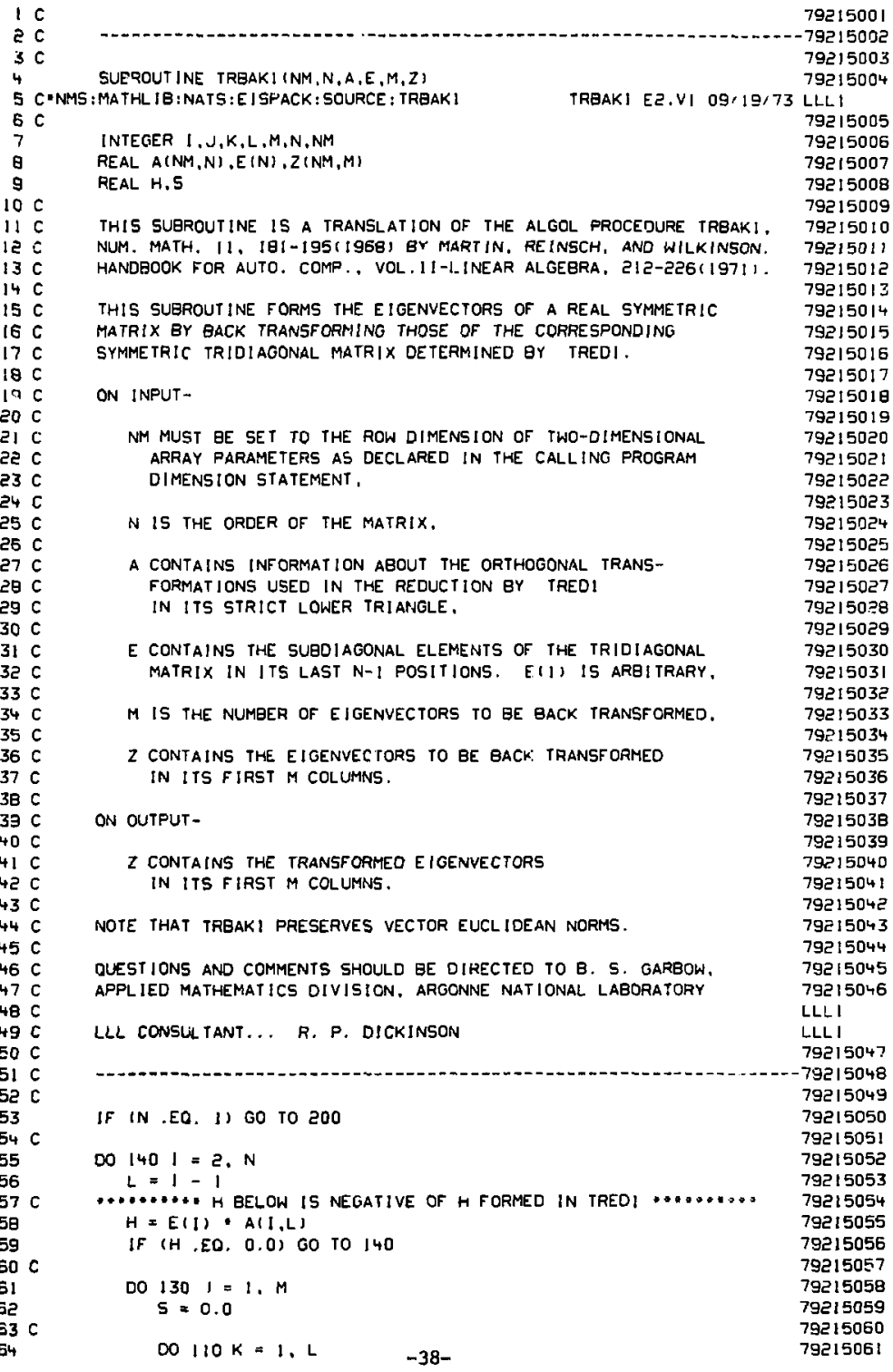




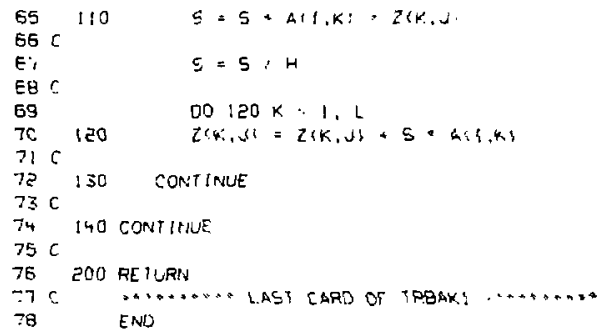

79215062 79215063 79215064 79215065 79215060 79215067 79215068 79215069 79215070 79215071 $792: 507 \overline{2}$ 79215073 $732150^{-1}$. 79215075 


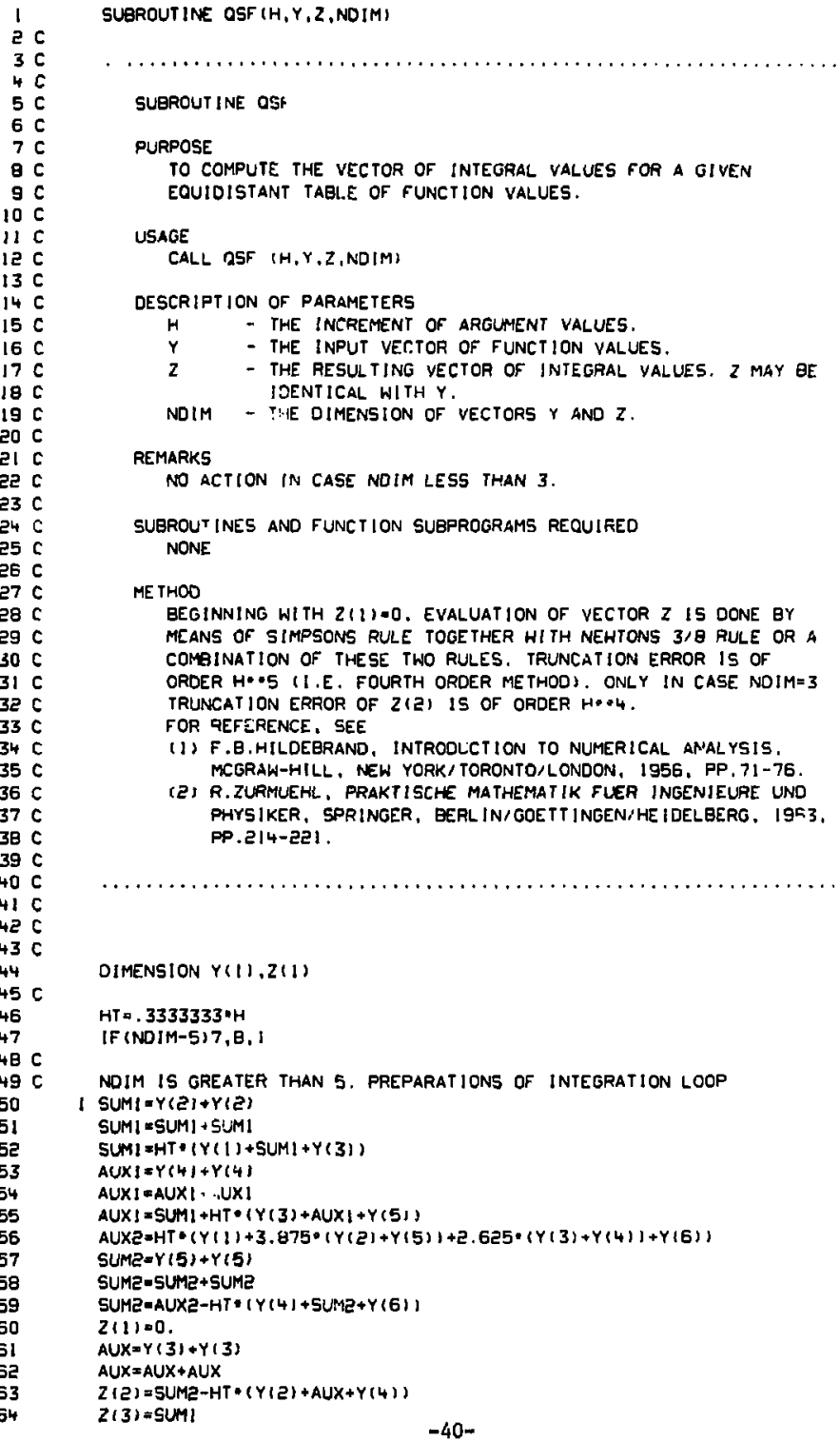




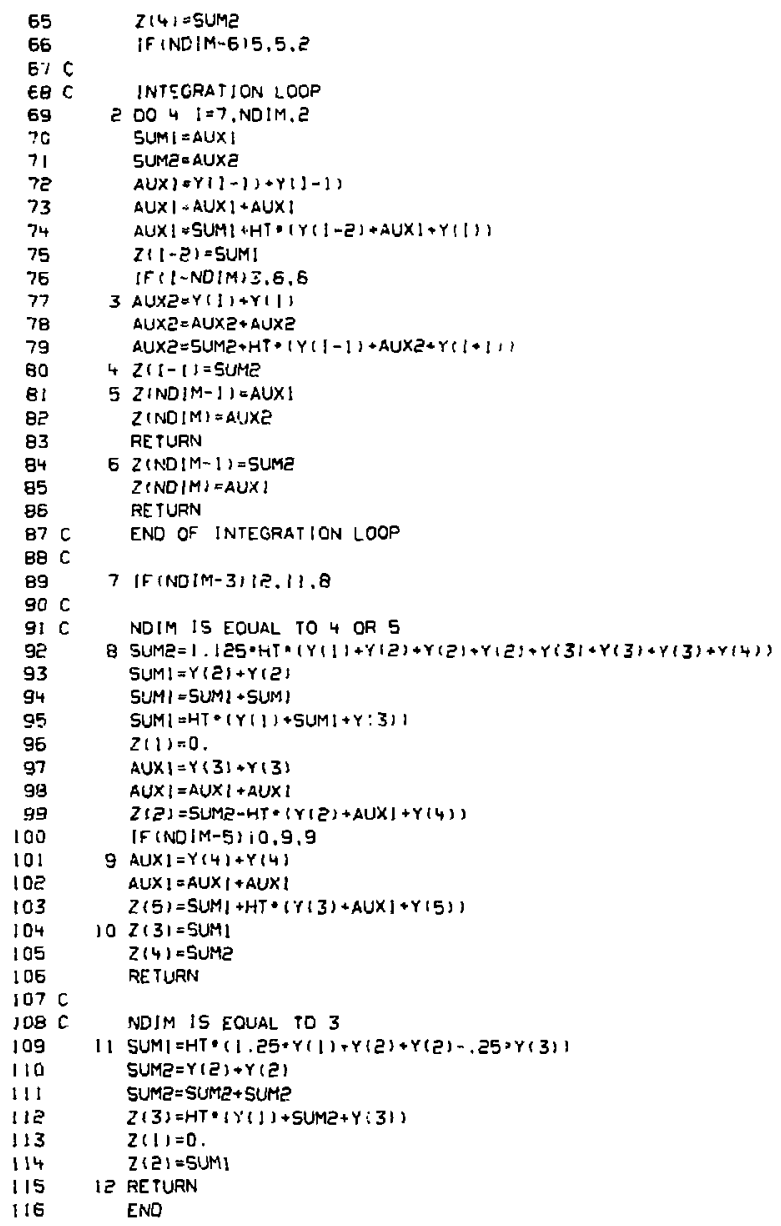


HUELSMAN

HUEL SMAN

HUELSMAN

HUEL SMAN

HUEL SMAN

HUELSMAN

HUELSMAN

HUELSMAN

HUELSMAN

HUEL SMAN

HUELSMAN

HUEL SMAN

HUEL SMAN

HUEL SMAN

HUEL SMAN

HUELSMAN

HUEL SMAN

HUELSMAN

HUELSMAN

HUEL SMAN

HUEL SMAN

HUEL SMAN

HUEL SMAN

HUEL SMAN

HUELSMAN

HUELSMAN

HUELSMAN

HUELSHAN

HUELSMAN

HUELSMAN

HUELSMAN

HUELSMAN

HUELSMAN

HUELSMAN 


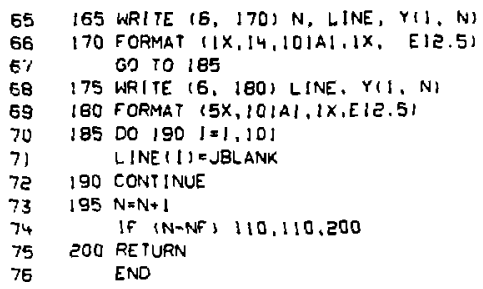

HUEL SMAN

MUEL SMAN

HUELSMAN

HUEL SMAN

HUELSMAN

HUEL SMAN

HUELSMAN

HUELSMAP

HUELSMAN

HUELSMAN 
$7 \mathrm{C}$

a C

$9 \mathrm{C}$

$10 \mathrm{C}$

$11 \mathrm{C}$

$12 \mathrm{C}$

$15 \mathrm{C}$

$14 \mathrm{C}$

$15 \mathrm{C}$

$16 \mathrm{C}$

$17 \mathrm{C}$

$18 \mathrm{C}$

$19 \mathrm{C}$

$20 \mathrm{C}$

215

ट2 $\mathrm{C}$

$23 \mathrm{C}$

$24 \mathrm{C}$

$25 \mathrm{C}$

$25 \mathrm{C}$

27 $\mathrm{C}$

$28 \mathrm{C}$

$29 \mathrm{C}$

$30 \mathrm{C}$

$31 \mathrm{C}$

$32 \mathrm{C}$

$33 \mathrm{C}$

34 C

$35 \div$

$36 \mathrm{C}$

$37 \mathrm{C}$

3日 C

$39 \mathrm{C}$

$40 \mathrm{C}$

4) C

पर C

$43 \mathrm{C}$

$44 \mathrm{C}$

$45 \mathrm{C}$

$46 \mathrm{C}$

$47 \mathrm{C}$

$48 \mathrm{C}$

$49 \mathrm{C}$

$50 \mathrm{C}$

$51 C$

$52 \mathrm{C}$

$53 \mathrm{C}$

$54 \mathrm{C}$

$55 \mathrm{C}$

$56 \mathrm{C}$

$57 \mathrm{C}$

$58 \mathrm{C}$

$59 \mathrm{C}$

$60 \mathrm{C}$

ह1 $C$

6e C

$63 \mathrm{C}$

$64 \mathrm{C}$

SUEROUT INE LF ILON (TIERO,T,FT,FTA,NT,F, FFZERO, FF , NF, B, IND, ITF )

THIS S'JGROUT INE PERFORMS THE FOURIER TRANSF ORM EITHER FROM TIME TO FREQUENCY

OR FREQUENCY TO TIME. LIMITATIONS ARE. THAT THE TIME FUNCTION MUST BE REAL

AND THE TIME FUNCTION MUST BE CAUSAL.

DESCRIPTION OF ARGUMENTS

TZERO - INITIAL VALUE OF TIME. THE CORAESPONOING FUNETION OF TIME IS SET TO ZERO BY THE SUBROUT INE

1 - ARRAY CONTAINING TIME VALUES IN ASCENDINO OROER

Ft - aRRAY CONTAINING FUNETION OF TIME VALUES IREALI

FTA - ADDITIONAL ARRAY LONTAINING FUNCTION OF TIME VALUES. USED ONLY IN FREQUENCY TO TIME MOOE

NT - NUMEER OF TIME FOINTS, EXCLUDING TZERO

F - aRRAY CONTAINING FREQUENCY VALUES IN ASCENDING ORDER

FFZERO - FUNCTION OF FREQUENCY JALUE (COMPLEX) AT ZERO FREQUENCY

FF - ARRAY ICOMPLEXI CONTAININO FUNCTION OF FREQUENCY VALUES

NF - NUMEER OF FREQUENCY POINTS, EXCLUSIVE OF ZERO FREQUENCY PDINT ASSOCIATEO WITH FFZERO

B - AUXILIARY ARRAY USED INTERNALLY ONLY BUT DIMENSIONED IN MAIN PROGRAM

IND - aUXILIARY ARRAY USED INTERNALLY ONLY BUT OIMENSIONED IN MAIN PRQGRAM

ITF - INTEGER INOICATOR SELECTING EITHER TIME TO FREQUENCY OR FREQUENCY TO TIME TRANSFORM

TO USE SUBROUTINE FOR TIME TO FREOUENCY TRANSFORM, PERFORM THE FOLLUWING

IN THE MAIN PROGRAM --

II SET ITF TO I

2) SET NT AND NF TO NUMBER OF TIME POINTS AND NUMBER OF FREQUENCY POINTS RESPECTIVELY

3) DIMENSION T, FT, aNO 8 hITH VALUE OF NT IFTA IS HOT USED AND MaY BE DIMENSIONED I

4) NAME FFZERO, FF, AND B, AS COMPLEX

5) DIMENSION F, FF. AND IND WITH VALUE OF NF

6) SUPPLY VALUES FOR TZERO, T, FT, NT, F, NF, AND I TF, S' SBROUTINE HILL RETURN FFZERO AND FF VALUES

TO USE SUEROUTINE FOR FREQUENCY TO TIME TRANSFORM, PERFORM FOLLOWINO IN MAIN PROGRAM --

1) SET ITF TO 0

2) SET NT AND NF TO NUHEER OF TIME POINTS AND NIMMER OF FREQUENCY POINTS, RESPECTIVELY

3) DIMENSION T. FT, FTA, AND INOM WITH VALUE OF NT

4) NAME FFZERO. FF, AND 9 COMPLEX

5) DIMENSION F, FF, AIND 0 WITH VALUE OF NF

6) SUPPLY VALUES FOR T, NT, F, FFZERO, FF, NF, AND ITF, SUBROUTINE WILL RETURN FT AND FTA VALUES. THE TRANSFORM IS COMPUTED TWO WAYS. 
FT CONTAINS THE RESULT OF THE TRANSTORM USING THE REAL PART OF FF MULTIPLIEO BY COSINE OF RADIAN FREQUENCY TIMES TIME, FTA CONTAINS THE RESULT OF THE TRANSFORM USING THE IMAGINARY PART OF FF MULTIPLIEO BY SINE OF RADIAN FREOUENCY TIMES TIME. USER SHOULD CHECK FOR CORRESPONDENCE OF THE TWO ANSWERS

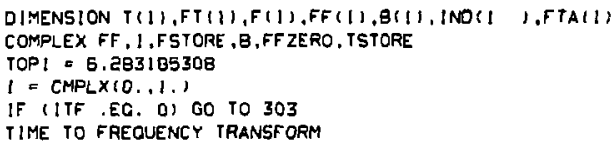


CFF(M) = FT(1) - CEXPI-1 $-W \cdot T(1) \cdot(T\{1)-T Z E R O)$

$4 F F(M)=F F(M), 2$.

COMOUTE F ILON PORTION

IF (INDIM) . E.O. NT) GO TO 2 I

FSTORE = FF (M)

$F F(M)=\quad F T($ INDM $) \cdot \operatorname{CEXP(-I}+W \cdot(T$ (INDM) - TZERO) $) ! a$

! W - FT(NT) - CEXPI-I * W ITINT) - TZEROI) $1 \cdot W+(I F T$ IINOMP)

2 - FT(INOM) , (T(INDMP) - TIIPIDM) ) - CEXPI-l - W - ITIINDM) -

3 TZEROI

GO TO 7

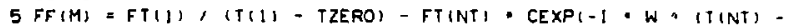

I TIEROH) $1 \cdot \mathrm{I}$

7 CONT INUE

$D O \geq ! N=$ INDMP, NT

$31 F F(M)=F F(M)+B(N) \cdot C E X P I-1 \cdot W \cdot I T(N)-T 7 E R O I I$

$F F(M)=-F F(M) \cdot$ CEXP $1-1 \cdot W \cdot$ TZERO) $(W, W)+F S T O R E$

2] CONTINUE

RE TURN

CREOUENCY TO TIME TRANSF ORM

303 CONT INUE

C DO LINEAR SEARCH FOR NUMBER TO DIVIDE TRAPAZOIDAL FROM FILON

DO $151 \mathrm{~N}=1, \mathrm{NT}$

TAU $=.1$, TINI

$M=1$

IF ITAU .LT. O.) GO TO 101

DO IHI M I I.NF

IF ITAU.LT, FIMI) GO TO IOI

141 CONTINUE

$[N D(N)=N F$

GO TO $|5|$

$101[N D(N)=M-1$

151 CONTINUE

C COMPUTE COEFFICIENTS

$N T P=N F-1$

$B(1)=(F F(2)-F F(1)),\{F(E)-F(1))-(F F(1)-F F Z E R O), F(1)$

$B(N F) \Rightarrow(F F(N T P)$ - FF (NF)), (F(NF) - F(NTP))

DO III $M=$ E.NTP

$N P=M \cdot 1$

$N L=M-1$

$B(M)=(F F(M P)-F F(M)),(F(N P)-F(M))-(F F(M)-F F(N L)), I F(M$ I $)$ - FINLI)

1!1 CONT INUE

COMPUTE TRANSFORM

DO $121 \mathrm{~N}=1$, NT

COMPUTE TRAPAZOIDAL PORTION

INDM = [NDIN]

INDMM = INDM - 1

INDMP = INOM + 1

TSTORE = CMPL $\times 10,0.1$

IF ([NDMA) 105,102, 106

106 FTIN) = REAL (FFZERO) * F(1) * REALIFF(1)) $\operatorname{COS}(T O P)=F(1)=T(N)$

$1, F(2)$

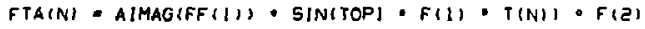

IF IINDM ,EQ. 2 ) GO TO 103

$D O|7| M=2$, INDMM

$N P=M+1$

$N L=M-1$

$F T(N)=F T(N) \cdot \operatorname{REAL}(F F(M)) \cdot \operatorname{COS}(10 P) \cdot F(M) \cdot T(N)) \cdot$ (F (NP) -

I $F[N(L)]$

$F T A(N)=F T A(N)+A(M A G(F F(M)) \cdot 5 I N(T O P I+F(M) \cdot T(N)) \cdot(F(N P)$

(- F (NLI)

$17 !$ CONTINUE

$F T(N)=F T(N)+R E A L(F F(I N D M)+C O S(T O P)=F($ INDM $)$ - T(N) ) 


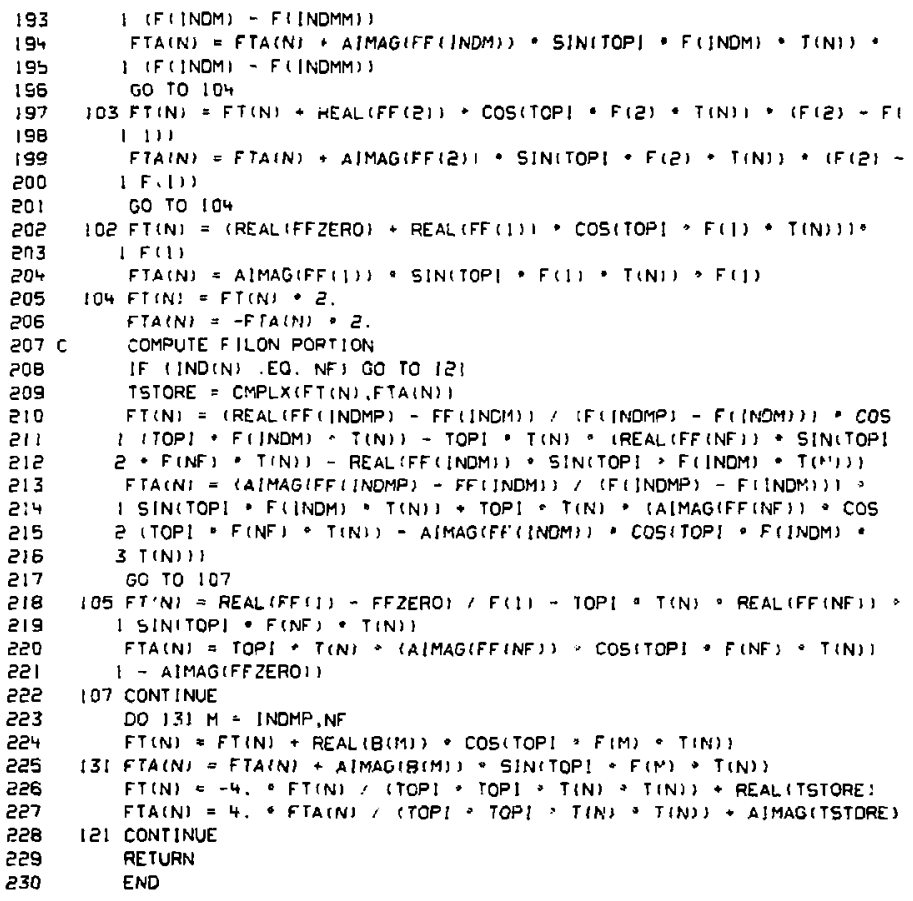

